\title{
Concentration profile behavioral from digestate television printed circuit board for metal recovery via electrolysis
}

\begin{abstract}
The production of electric and electronic products is one of the fastest growing businesses in the world. This scenario creates increasing amount of electric and electronic waste in our waste stream and it becomes a common problem facing by the world. In this study, the concentration profile behavioral of a television printed circuit board (PCB) is being investigated for future electrolysis treatment. Prior to that, a PCB is cut into several pieces and is digested via aqua-regia. The digestate from the digestion is analyzed using Inductively Coupled Plasma (ICP-MS) to estimate the present of metals with their range of corresponding concentration value and Thermogravimetric Analysis (TGA) is carried out to investigate the thermal decomposition of the filtrate from the digestion. The major metal elements that contain in the digestate are $\mathrm{Cu}(3,123-6,994 \mathrm{mg} \mathrm{L}-1), \mathrm{Pb}$ and $\mathrm{Fe}$ and traces of two precious metal namely (6.3-13.8 mg L-1) and $\mathrm{Au}(0.2-5.4 \mathrm{mg} \mathrm{L}-1)$. Three degradation stages are observed in the TGA analysis (two days after ovenate at $102^{\circ} \mathrm{C}$ ) namely moisture removal with $10.3 \mathrm{wt} \%$, volatile matters removal with $14.45 \mathrm{wt} . \%$ and non-volatile removal with 16.7 $\mathrm{wt} \%$. The ash value after $1000 \mathrm{oC}$ heating in the TGA is almost $60 \mathrm{wt}$. \%. An electrolysis process is then proposed in order to recover selectively valuable metals, such as $\mathrm{Cu}, \mathrm{Pb}, \mathrm{Ni}$, $\mathrm{Ag}$ and $\mathrm{Au}$.
\end{abstract}

Keyword: Aqua-regia; E-waste; Electrolysis; Metal recovery 